\title{
Prevalence and Factors Associated with Nutrition Label Use among Selected Filipino Adults
}

\author{
Denniese C. Sy and Ernani R. Bullecer \\ Department of Nutrition, College of Public Health, University of the Philippines Manila
}

\begin{abstract}
Objective. This study has been conducted to determine the prevalence of nutrition label use and the factors associated with it among adults in selected communities in Los Baños, Laguna.

Methods. This is an analytical cross-sectional study, which conducted face-to-face interview using a developed questionnaire, among 440 adults in the top four barangays with highest population in Los Baños, Laguna using twostage sampling design. In the first stage, three puroks were randomly selected in each barangay, while households were selected using systematic sampling in the second stage. An eligible adult in each selected household was invited to participate in the study.
\end{abstract}

Results. Study findings revealed that nutrition label use among adults in the selected communities was $87.73 \%$. Factors found to be associated with nutrition label use were: 1 ) intention to use nutrition label (OR: $4.37 ; 95 \%$ $\mathrm{Cl}$ : 1.77-10.82), 2) enough perceived time-spent on shopping (OR: 2.16; 95\% Cl: 1.17-4.01), and 3) searching for specific information (OR: 4.77; 95\% Cl: 2.55-8.93).

Conclusion. These study findings can be used in promoting and increasing nutrition label use in the country and serve as basis for improvement of nutrition labeling policies. Moreover, this study can serve as a reference in the development and strategy-planning of interventions and programs especially in promoting healthy diets.

Key Words: nutrition label use, prevalence, associated factors

\section{INTRODUCTION}

The leading causes of death around the globe are noncommunicable diseases (NCD) and almost $80 \%$ of NCD deaths take place in low- and middle-income countries. ${ }^{1}$ In the Philippines, different risk factors for the development of NCDs are on the rise. Among adults aged 20 years and over, the prevalence of overweight or obese almost doubled from $16.6 \%$ to $31.1 \%$ from 1993 to 2013 . The prevalence of high fasting blood glucose among adults continuously increased from 3.4\% in 2003 to 5.6\% in 2013. Dyslipidemia was common as well in which almost half of adults have borderline to high total cholesterol levels (47.2\%) and borderline to high LDL-cholesterol (47.5\%), while nearly three fourths $(71.0 \%)$ had low HDL-cholesterol and one Poster presented at the World Public Health Nutrition Congress 2020, April-June, 2020, Brisbane, Australia.

Corresponding author: Denniese C. Sy, RND, MSPH

Department of Nutrition

College of Public Health

University of the Philippines Manila

625 Pedro Gil St., Ermita, Manila

1000 Philippines

Email: sydenniese@gmail.com third (38.7\%) has borderline to very high triglyceride level. ${ }^{2}$ With these continuously rising problems of risk-factors in the country, interventions are highly needed to prevent further escalation.

A possible solution to this is the identified evidencebased "best buy" interventions for NCDs by the WHO, in which, in terms of unhealthy diet and physical inactivity as risk factor, public awareness through mass media on diet 
and physical activity is one of the identified interventions. ${ }^{3}$ As included in the WHO recommendations to provide assistance to the public in selecting healthier choice of food, one of the objectives of nutrition label is to provide information on available options to consumers and to encourage the use and production of food products that are healthy. ${ }^{4}$ Furthermore, studies have already reported associations and effects of nutrition labelling and its use with improved population health outcomes, healthy diet, and production of more products with lower amounts of negative nutritional attributes. ${ }^{1,5,6}$

Through provision of important and correct information on healthy food choices for a balanced diet, nutrition labeling may play a significant role in the prevention and control of non-communicable diseases. ${ }^{2}$ However, the results of the 8th National Nutrition Survey (NNS) reported that only $12.3 \%$ read nutrition facts, while related studies have reported higher percentages showing mixed results., ${ }^{2,7}$ In addition, extensive research regarding the use of nutrition label and its determinants were mostly from developed countries and there is limited information to be able to determine factors that might have significant roles in nutrition label use in the country, which in turn, can be used to improve and increase its utilization. ${ }^{9-12}$

Hence, this study determined the prevalence of nutrition label use and if the following factors were associated with nutrition label use among adults in selected communities in Los Baños, Laguna; sex, age, civil status, educational attainment, occupation, and family monthly income among socio-demographic factors; specific dietary needs, weight control, disease diagnosis, body mass index (BMI), nutrition knowledge, and nutrition label understanding among health- related factors; interest in healthy eating habits, exercise level, and perceived time spent on shopping among lifestyle factors; and search for specific information and intention to use nutrition label in other factors.

\section{METHODS}

\section{Study Design}

A cross-sectional, analytic study design was used in this research.

The sampling and target population of the study were adults in the top four barangays with highest population in Los Baños, Laguna. To minimize transportation and costs, as well as due to time and budget constraints, only the top four populated barangays will be included in the study based on the 2010 NSO Census. As shown in Figure 1, a twostage sampling design was used in this study and the target number of participants was 114 adults in each barangay. The study sample size was computed using Open Epi with the following: confidence level at 95\%, margin of error of 5\%, design effect of 1.0 and power set at $80 \%$, with an additional $22 \%$ as allocation for occurrence of drop-outs.

\section{Study Participants}

In each selected household per barangay, one adult, aged 18 to 59 years old, was invited to participate in this study through face-to-face interview. Pregnant female adults, on the other hand, were excluded. In case of a respondent's refusal to participate or withdraw in the study, at any point in time during the conduct of the research, even if they agreed earlier; all the collected data from the respondent were withdrawn and not included in the study.

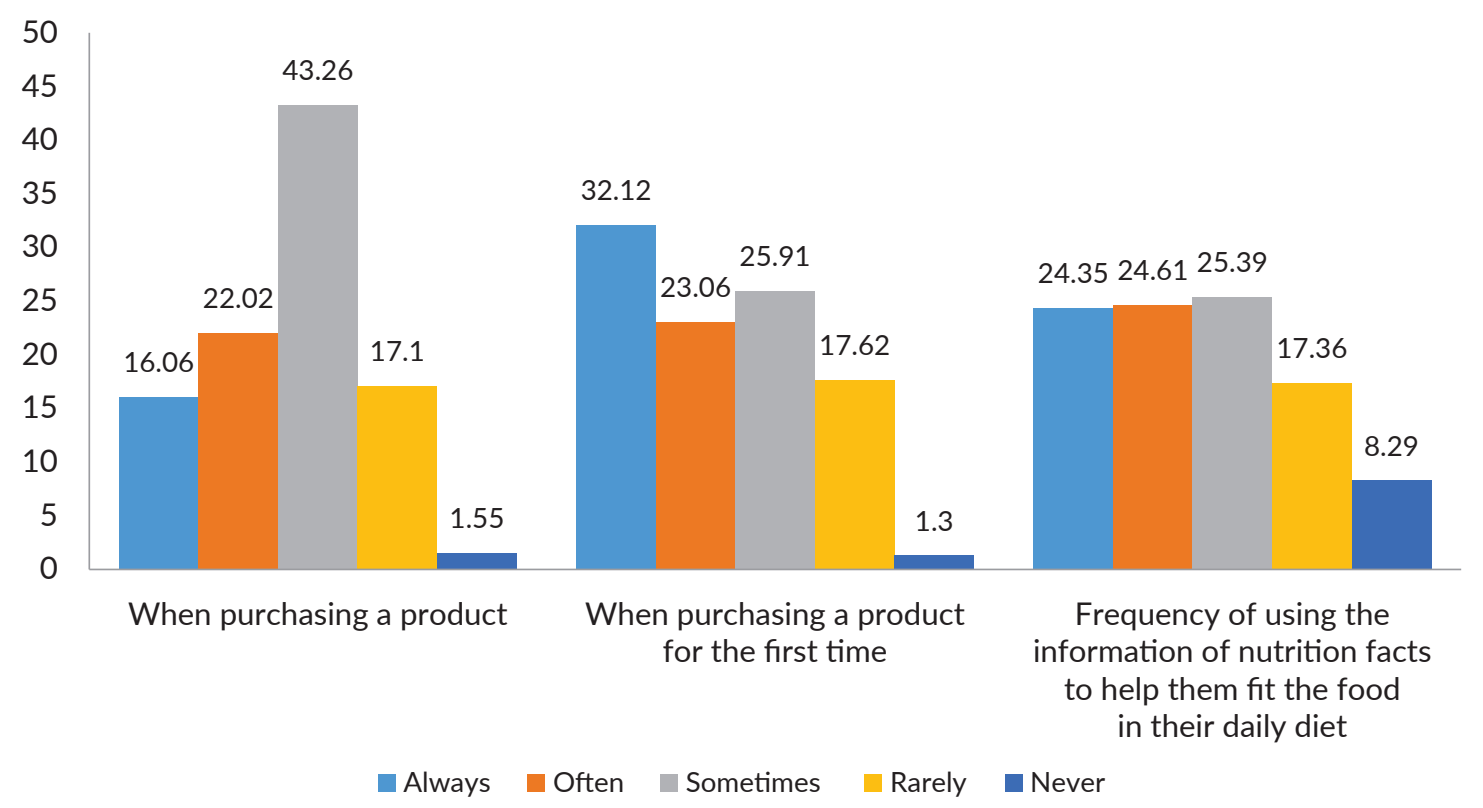

Figure 1. Frequency of nutrition label use among adults who use nutrition label in selected communities in Los Baños, Laguna, 2019 ( $n=386)$. 


\section{Data Collection Procedure}

The setting of the study was at the Municipality of Los Baños in the province of Laguna. It has 14 barangays and a population of $109,210 \cdot{ }^{13}$ Barangays can be categorized as rural or urban areas and three out of the top four barangays with the highest population were categorized as rural areas..$^{14}$

A trained data collector went to each selected households and conducted collection of data with a Barangay Nutrition Scholar (BNS) or Barangay Health Worker (BHW) for endorsement. After which, the BNS or BHW left the place for the meantime to ensure that no influence was given to study participants. In case of participant's unavailability during the first visit, only one follow-up was conducted the following day. If still not available after one follow-up, then the data collector proceeded to the next selected household. Likewise, the data collector proceeded to the next selected household in case of refusal to participate in the study.

\section{Measurement of Study Variables}

A face-to-face interview was conducted for data collection. The use of nutrition label use, which pertained to reading of nutrition information on food labels or packages when buying food, was measured based from the study by Marrieta et al. ${ }^{15}$ Different socio-demographics, health-related factors, lifestyle factors and other factors were measured as well to determine its association with nutrition label use. Specifically, the sex, age, civil status, education, occupation and family monthly income of the participants were asked for socio-demographics. Having specific dietary needs or diet being followed, practice of weight control, occurrence of disease diagnosis, body mass index (BMI), nutrition knowledge based from the study by Kliemann et al., and nutrition label understanding based from study by Mackison et al. were assessed among health-related factors. Interest in healthy eating habits based from study by Roininen, Lahteenamki and Tuorila, exercise level, and perceived time spent on shopping were measured among lifestyle factors. ${ }^{16,17,18}$ Furthermore, search for specific information, and intention to use nutrition label based from study by Francis et al. were assessed for other factors. ${ }^{19}$

\section{Data Analysis}

All measured variables from the respondents were encoded in Microsoft Excel, while editing was done prior to analysis to ensure that there were no outliers, missing values and inconsistencies. To meet the objectives of the study, descriptive and inferential statistics were utilized. Proportion and interval estimates were used to report prevalence of nutrition label use. On the other hand, to determine the factors associated with nutrition label use, multiple logistic regression was utilized to determine the relationship between binary response variable and a set of explanatory variables. A backward elimination method was specifically used to fully determine the factors associated with nutrition label use and level of significance was set at 0.05 . Stata software program version 12 was used for data analysis in this study.

\section{Ethical Considerations}

Study participants were provided with sufficient information about the study through informed consent forms which explained the procedures for participant selection; information regarding methods and components of the study; non-disclosure of information to ensure confidentiality and anonymity of the participants; duration, risk and benefits of the study; and rights of the respondents. No remuneration was given to the respondents for participating in the study. But, a token of appreciation was given in the form of snacks.

Furthermore, this study was conducted in accordance with the guidelines laid down in the National Ethical Guidelines for Health Research 2017 and all study procedures and protocols involving the study respondents were reviewed and approved for implementation by University of the Philippines Manila Research Ethics Board (UPMREB) with UPM-REB Protocol Code 2018-596-01 and RGAO Registration No. 2018-1151.

\section{RESULTS}

The target number of participants was 114 adults per barangay from the selected households. However, 9 adults from Brgy. Mayondon, 1 adult from Brgy. San Antonio, and 6 adults from Brgy. Bayog were not included in the study due to unavailability during data collection. All the data collected from 440 adults who participated in the study were complete and were used for data analysis.

\section{Description of Participants}

A summary of the characteristics of the study participants can be seen in Table 1. Majority of the participants were females (89\%) and almost half (47\%) were young adults (18-35 years). In terms of education, more than half of the study participants (58\%) were high-school graduate. More than half of the study participants were married (56\%) and were unemployed (55\%). In addition, among the study participants, almost half (45\%) have monthly family income of below Php 8,000.

\section{Nutrition Label Use}

Results, as can be seen in Table 2, revealed that nutrition label use among adults in the selected communities was 87.73\% (95\% CI: 84.30-90.49\%). The prevalence also varied among categories of each factors.

Moreover, as shown in Figure 1, the data revealed that among those who use nutrition labels, $43.26 \%$ 'sometimes' use it when purchasing a product, $22.02 \%$ 'often' use it, and only $16.06 \%$ 'always' use it. When purchasing a food product for the first time, $32.12 \%$ 'always' use nutrition label, 25.91\% 


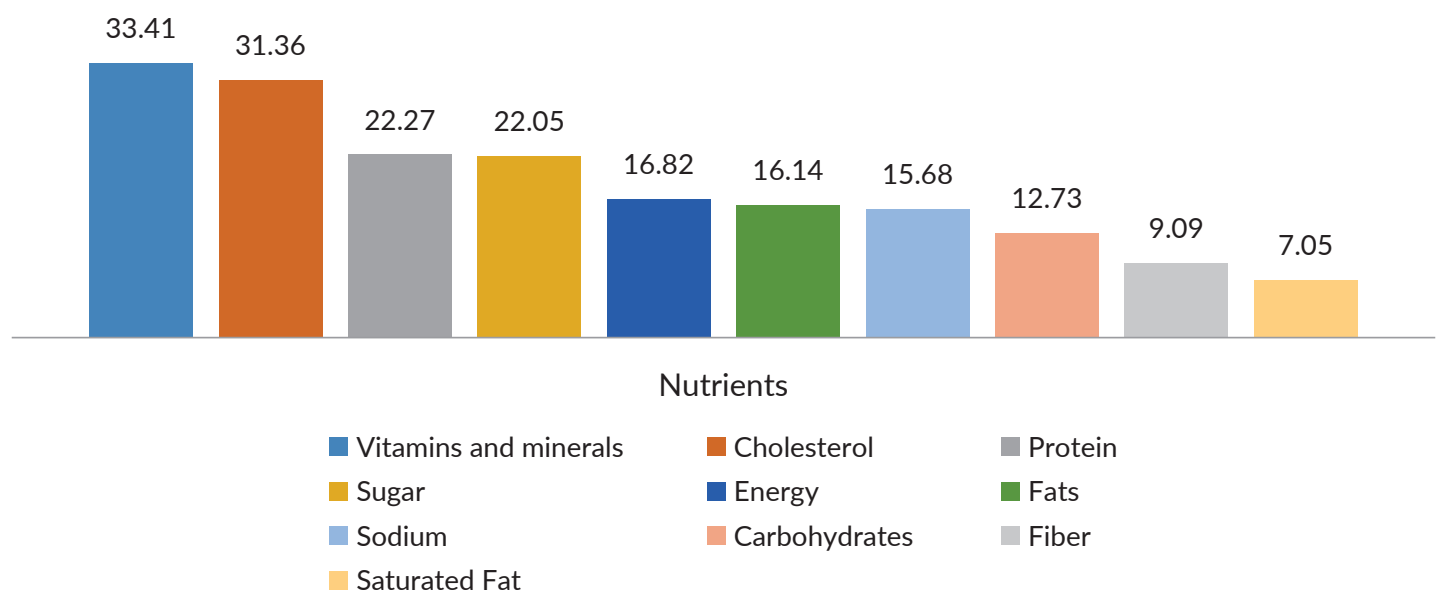

Figure 2. Proportion of adults in selected communities in Los Baños, Laguna who searched for specific nutrients in nutrition facts table, 2019 ( $n=440)$.

Table 1. Characteristics of participating adults in selected communities in Los Baños, Laguna, 2019 ( $n=440)$

\begin{tabular}{|c|c|c|}
\hline Characteristics & No. & Percent (\%) \\
\hline \multicolumn{3}{|l|}{ Sex } \\
\hline Male & 47 & 10.68 \\
\hline Female & 393 & 89.32 \\
\hline \multicolumn{3}{|l|}{ Age } \\
\hline Older adults & 32 & 7.27 \\
\hline Middle-aged & 200 & 45.45 \\
\hline Young adults & 208 & 47.27 \\
\hline \multicolumn{3}{|l|}{ Education } \\
\hline Elementary & 101 & 22.95 \\
\hline High School & 255 & 57.95 \\
\hline Vocation & 5 & 1.14 \\
\hline College & 79 & 17.95 \\
\hline \multicolumn{3}{|l|}{ Civil Status } \\
\hline Single & 163 & 37.05 \\
\hline Separated & 16 & 3.64 \\
\hline Widow & 15 & 3.41 \\
\hline Married & 246 & 55.91 \\
\hline \multicolumn{3}{|l|}{ Occupation } \\
\hline Student & 11 & 2.50 \\
\hline Retired & 1 & 0.23 \\
\hline Employed & 188 & 42.73 \\
\hline Unemployed & 240 & 54.55 \\
\hline \multicolumn{3}{|l|}{ Family Monthly Income } \\
\hline Below Php 8,000 & 199 & 45.23 \\
\hline Php 8,000 - 16,000 & 188 & 42.73 \\
\hline Php 16,000 - 32,000 & 49 & 11.14 \\
\hline Php 32,000 - 80,000 & 4 & 0.91 \\
\hline
\end{tabular}

Table 2. Nutrition label use among adults in selected communities in Los Baños, Laguna, 2019 ( $n=440)$

\begin{tabular}{lrcc}
\multicolumn{1}{c}{ Factor } & No. & $\begin{array}{c}\text { Prevalence } \\
\text { (\%) }\end{array}$ & $\begin{array}{c}\text { 95\% Confidence } \\
\text { Interval }\end{array}$ \\
\hline Use of Nutrition Label & 386 & 87.73 & $84.30-90.49 \%$ \\
Non-use of Nutrition Label & 54 & 12.27 & $9.11-15.70 \%$ \\
\hline
\end{tabular}

'sometimes' use it, and 23.06\% 'often' use it among the adults in the study. While, when buying food products, $25.39 \%$ 'sometimes' use the information of nutrition facts to help them fit the food in their daily diet, $24.61 \%$ 'often' use it and $24.35 \%$ 'always' use it.

These responses provided insight that the frequency of nutrition label use varied among the adults and the most frequent use of nutrition label was only 'sometimes'.

In addition, among the information in a nutrition label, the ranking of nutrients being searched for by the study participants were as follow, as shown in Figure 2:1) Vitamins and minerals (33.41\%), 2) Cholesterol (31.36\%), 3) Protein (22.27\%), 4) Sugar (22.05\%), 5) Energy (16.82\%), 6) Fats (16.14\%), 7) Sodium (15.68\%), 8) Carbohydrates (12.73\%), 9) Fiber (9.09\%), and 10) Saturated fat (7.05\%).

\section{Factors Associated with Nutrition Label Use}

Meanwhile, it was revealed in the study findings, as shown in Table 3, that initially, the following factors had statistically significant crude association with nutrition label use: sex (OR: 2.14; 95\% CI: 1.00-4.61), separated civil status (OR: 0.25; 95\% CI: 0.08-0.75), weight control (OR: 1.68; 95\% CI: 0.91-3.08), normal body mass index (OR: 2.30; 95\% CI: 1.06-4.99), overweight body mass index (OR: 3.38; 95\% CI: 1.22-9.39), moderate nutrition label understanding (OR 1.56; 95\% CI: 0.74-3.28), high nutrition label understanding (OR: 1.64; 95\% CI: 0.76-3.51), perceived time-spent on shopping (OR: 1.95; 95\% CI: 1.10-3.46), seldom exercise (OR: 2.65; 95\% CI: 1.31-5.37), interest in healthy eating (OR:3.78; 95\% CI: 1.10-13.00), search for specific information (OR: 5.20; 95\% CI: 2.83-9.59), and intention to use nutrition label (OR: 5.26; 95\% CI: 2.25-12.29).

However, as shown in Table 4, only the following factors were associated with nutrition label use using multiple logistic regression: 1) high intention to use nutrition label, 2) enough perceived time-spent on shopping, and 3) searching for specific information. 
Table 3. Crude association of factors with nutrition label use

\begin{tabular}{|c|c|c|}
\hline Factors & OR $(95 \% \mathrm{Cl})$ & p-value \\
\hline \multicolumn{3}{|l|}{ Socio-Demographics } \\
\hline Sex & $2.14(1.00-4.61)$ & 0.051 \\
\hline \multicolumn{3}{|l|}{ Age } \\
\hline Middle-Aged & $0.88(0.49-1.57)$ & 0.654 \\
\hline Older Adults & $2.05(0.46-9.10)$ & 0.346 \\
\hline \multicolumn{3}{|l|}{ Education } \\
\hline High School & $1.31(0.67-2.55)$ & 0.430 \\
\hline Vocation & $0.70(0.07-6.68)$ & 0.755 \\
\hline College & $1.55(0.62-3.86)$ & 0.349 \\
\hline \multicolumn{3}{|l|}{ Civil Status } \\
\hline Separated & $0.25(0.08-0.75)$ & 0.013 \\
\hline Widow & $0.59(0.15-2.27)$ & 0.444 \\
\hline Married & $1.37(0.73-2.55)$ & 0.324 \\
\hline \multicolumn{3}{|l|}{ Occupation } \\
\hline Retired & - & - \\
\hline Employed & $0.65(0.08-5.32)$ & 0.690 \\
\hline Unemployed & $0.76(0.09-6.14)$ & 0.794 \\
\hline \multicolumn{3}{|l|}{ Family Monthly Income } \\
\hline Php8000-16,000 & $1.03(0.56-1.92)$ & 0.913 \\
\hline Php 16,000 - 32,000 & $0.82(0.33-2.04)$ & 0.673 \\
\hline Php 32,000 - 80,000 & $0.41(0.04-4.12)$ & 0.450 \\
\hline \multicolumn{3}{|l|}{ Health-Related Factors } \\
\hline Specific dietary needs & $1.46(0.66-3.21)$ & 0.352 \\
\hline Weight control & $1.68(0.91-3.08)$ & 0.096 \\
\hline Disease Diagnosis & $1.35(0.67-2.72)$ & 0.403 \\
\hline \multicolumn{3}{|l|}{ Body Mass Index (BMI) } \\
\hline Normal & $2.30(1.06-4.99)$ & 0.036 \\
\hline Overweight & $3.38(1.22-9.39)$ & 0.019 \\
\hline Obese & $1.23(0.45-3.42)$ & 0.686 \\
\hline \multicolumn{3}{|l|}{ Nutrition knowledge } \\
\hline Moderate & $1.05(0.35-3.15)$ & 0.930 \\
\hline High & $1.77(0.41-7.67)$ & 0.446 \\
\hline \multicolumn{3}{|l|}{ Nutrition Label Understanding } \\
\hline Moderate & $1.56(0.74-3.28)$ & 0.241 \\
\hline High & $1.64(0.76-3.51)$ & 0.206 \\
\hline \multicolumn{3}{|l|}{ Lifestyle Factors } \\
\hline Perceived Time-spent on shopping & $1.95(1.10-3.46)$ & 0.022 \\
\hline \multicolumn{3}{|l|}{ Exercise } \\
\hline Seldom & $2.65(1.31-5.37)$ & 0.007 \\
\hline Regular & $1.33(0.64-2.73)$ & 0.445 \\
\hline Interest in healthy eating & $3.78(1.10-13.00)$ & 0.035 \\
\hline \multicolumn{3}{|l|}{ Other Factors } \\
\hline Search for specific Information & $5.20(2.83-9.59)$ & 0.000 \\
\hline Intention to use nutrition label & $5.26(2.25-12.29)$ & 0.000 \\
\hline
\end{tabular}

Controlling for other variables, the odds of nutrition label use were 4.37 times as high among adults with high intention to use nutrition label as those with low intention to use nutrition label (95\% CI: 1.77-10.82).Similarly, the odds of nutrition label use were 2.16 times as high among adults with enough perceived time-spent on shopping as those with limited perceived time- spent on shopping (95\% CI: 1.174.01).Lastly, the odds of nutrition label use were 4.77 times
Table 4. Predictors of Nutrition Label Use

\begin{tabular}{lcc}
\multicolumn{1}{c}{ Factors } & Adjusted OR (95\% Cl) & p-value \\
Intention to Use Nutrition Label & & \\
$\quad$ Low & 1.00 & - \\
$\quad$ High & $4.37(1.77-10.82)$ & 0.001 \\
Perceived time-spent on shopping & & \\
$\quad$ Limited & 1.00 & - \\
$\quad$ Enough & $2.16(1.17-4.01)$ & 0.014 \\
Search for Specific Information & & \\
$\quad$ No & 1.00 & - \\
$\quad$ Yes & $4.77(2.55-8.93)$ & 0.000 \\
\hline
\end{tabular}

as high among adults who search for specific information on nutrition label as those who do not search for specific information (95\% CI: 2.55-8.93).

\section{DISCUSSION}

\section{Nutrition Label Use}

The estimated prevalence of nutrition label use $(87.73 \%$, 95\% CI: 84.30-90.49\%) in this study was higher compared to related local studies of Talavera et al., which had $56 \%$ nutrition label use, study of Baliclic et al., which had 38\% and results of $12.3 \%$ from 2013 NNS., ${ }^{2,8}$ However, the cause of higher estimate in the research findings can be due to a number of reasons. First, three out of the four top populated barangays included in this study were categorized as rural areas; namely, Brgy. Bayog, Mayondon, and San Antonio. ${ }^{13}$ It has been found that those who live in non-city or rural areas were more likely to use the nutrition information in a review by Dichroutis et al. ${ }^{20} \mathrm{~A}$ possible explanation for this is that individuals in non-metro areas have a generally slower lifestyle and have more time to shop than do individuals in urban areas. Hence, they are able to devote more time to examining nutritional information on food packages than others. ${ }^{21}$ In addition, the Municipality of Los Baños had already been an awardee of Nutrition Honor Award in 2001. It is the highest and most prestigious award given to a local government unit that showed remarkable performance in nutrition program management for the past three years. ${ }^{22}$ The results might also have been a reflection of positive results due to significant nutrition program management in the municipality as early as 2001 .

This study also utilized relatively larger sample size compared to 65 participants in the study by Talavera et al. and 100 participants in the study by Baliclic. et al., which might have affected positively the precision of the study. ${ }^{7,8}$

Moreover, the measurement of nutrition label use based from a foreign study, might have caused a difference in the method of data collection as well, through a possible difference in the cultural approach of questions, affecting the estimation of prevalence..$^{15}$

Also, despite the high prevalence of nutrition label use found in this study, it is important to note that the prevalence varied among the adults in the selected communities in terms of different variable settings. Furthermore, having 'sometimes' 
as the most frequent use of nutrition label when purchasing product and to help in fitting foods in daily diet, warrants an improvement in the practice of reading nutrition labels. Promotions of nutrition label use, its importance and how to use different nutrition information can help in increasing proportions of adults who use nutrition labels and the frequency of its use.

\section{Factors Associated with Nutrition Label Use}

Initially, the following factors had significant crude association with nutrition label use: sex, separated civil status, weight control, normal body mass index, overweight body mass index, moderate nutrition label understanding, high nutrition label understanding, seldom exercise, and interest in healthy eating. However, there was insufficient evidence of association after utilization of multiple logistic regression. Despite this, these factors should be considered especially in program planning and implementation as these could have a potential influence with regards to nutrition label use among adults as shown in numerous studies.

In terms of sex, females were more likely to use nutrition label..$^{9-12}$ In terms of influence of civil status, there are variations in consideration of factors while purchasing food product before and after marriage. It is also possible that having children in the family might have an effect on the purchasing decision-making to take care of children's food. ${ }^{23}$ Meanwhile, in terms of weight control, it can have an influence due to controlling of diet intake and consciousness on gaining of weight. Similarly, in terms of BMI, nutrition label, as a source of information, is one of the ways of monitoring calorie and nutrient intake. On the other hand, nutrition label understanding, similar to nutrition knowledge, may facilitate label use by increasing its perceived benefits and by increasing its efficiency. Also, consumers with more knowledge were less skeptical towards nutritional information. ${ }^{20}$ On the other hand, with regards to exercise, regular exercise have been shown to have an association with nutrition label use, but it is possible that those who do not have regular exercise might tend to be more conscious of their diet intake and hence, can use nutrition label as a tool for healthier food selection. ${ }^{10}$ Lastly, interest in healthy eating can affect the use of nutrition label. ${ }^{24}$ Moreover, considerations of these factors in programs and interventions planning will provide comprehensive approach in addressing potential barriers and in improving the use of nutrition label.

On the other hand, the result which revealed that high intention to use nutrition label was associated with nutrition label use has demonstrated the effectiveness of the theory of planned behavior by Azjen in predicting the behavior. It states that the stronger the intention to do a certain behavior, the more likely that the behavior will be performed..$^{25}$ Hence, it is suggested that to increase the intention to use nutrition label; its determinants, namely, the attitude, subjective norms, and perceived behavioral control on nutrition label, should be considered. Promotions and nutrition education programs should be planned to ensure that the three determinants of behavior intention would be focused on.

Meanwhile, having enough perceived time-spent on shopping, as one of the associated factors of nutrition label use, was consistent with the findings by Campos et al. that those who spend more time or who have more time for groceries were more likely to use labels. ${ }^{15}$ This could be due to the fact that time pressure has been found to limit individuals' search of nutritional information. ${ }^{20}$ Hence, it is important that consumers should be knowledgeable on nutrition information so that they know exactly what needs to be looked out for and how to interpret it and the information should be easy to locate in nutrition label. ${ }^{26}$

Lastly, searching for specific information, one of the associated factors of nutrition label use, was consistent with the study by Rasberry et al. ${ }^{27}$ This might be due to the fact that consumers would refer to nutrition labels to know about the content of a calorie or nutrient in a product. This suggest that raising the awareness of consumers about diet-disease relationship would help in motivating them in monitoring their calorie and nutrient intake through the use of nutrition label.

Also, the results in terms of nutrient information most frequently read were similar to the findings by Song et al., in which the top nutrients were proteins followed by vitamins among Chinese consumers. ${ }^{28}$ But, the variation in the actual ranking of nutrients might have been brought by the difference in the needs and considerations of study participants for each study, suggesting that the search for specific information by each respondent may have been affected by their respective purpose of purchasing.

Despite of addressing limited local studies regarding nutrition label use through this research, the limitations of this study should be noted. First, some variables measured will have low power of test (lower than 80\%) due to having high computed minimum sample size which was not feasible for limited time and budget of data collection. But, those variables were still measured due to potential influence on nutrition label use. Second, in spite of including many possible factors in this study to be able to determine its association with nutrition label use, there might still be other factors that were not included in this research that may also have a substantial effect on the use of nutrition label such as household size, placing of importance on food attributes, use of nutritional supplements, and smoking status. In addition, the answers or responses of respondents on face-to-face interview might be prone to respondent bias or social-desirability bias. Even though a pre-testing of the interview questionnaire was conducted to ensure clarity of questions, problems such as difference in the interpretation of interview questions among participants could also still occur. 


\section{CONCLUSION AND RECOMMENDATIONS}

The prevalence of nutrition label use among the adults in the selected communities was $87.73 \%$. Despite of having high prevalence, the frequency of use varied among the adults and most of them used nutrition label only 'sometimes'. Meanwhile, the following factors were found to be associated with nutrition label use, namely: 1) intention to use nutrition label (OR: 4.37; 95\% CI: 1.77-10.82), 2) enough perceived time-spent on shopping (OR: 2.16; 95\% CI: $1.17-4.01$ and 3) searching for specific information (OR: 4.77; 95\% CI: 2.55-8.93). Results suggest that these should be given focus and considered during planning of promotions, education and programs and development of interventions to increase nutrition label use. In addition, although many factors were found to have insufficient evidence of association, the respective influences of each factor in the socio-demographics, health-related factors, lifestyle factors and other factors with nutrition label use, should still be considered for a comprehensive approach. This is also to ensure that potential barriers would be addressed and those who are more likely to use nutrition label would be maintained, while those with characteristics who do not use nutrition label would be included as well.

Meanwhile, as suggested by study findings which can be used as reference in improvement of nutrition labeling policies; to encourage those who have limited perceived time spent on shopping, the addition of front-of-pack label could help as a complementary system to nutrition facts table. It could also be used to simplify nutrition information found in nutrition facts table and are placed in front of packages for easier access.

Also, improving nutrition knowledge and nutrition label understanding among consumers is highly needed since if they know exactly what they need to looked for, its importance and if they know how to understand the information, then nutrition label use could be done efficiently. Likewise, since there is different nutrient information on nutrition labels, it is important that consumers know the relationship or importance of these with health and diseases to motivate them in monitoring the calorie and nutrient amounts found in nutrient labels and consider them in decision making of food purchasing. With this, it is important that calorie and nutrient information should be given focus as well in promotion and nutrition education about nutrition label use to increase not only the knowledge and familiarity of consumers but also to maintain and increase interest in search of specific information and use of nutrition labels. Important topics that must be included in education programs, aside from significance of nutrition label use and implication of different nutrition information on nutrition label, are the following: awareness of diet-disease relationship, healthy food choices, nutritional guidelines and recommendations. More studies should also be conducted for monitoring, to collect more information regarding nutrition labels and be used in further improving and increasing its use.

\section{Statement of Authorship}

Both authors participated in data collection and analysis, and approved the final version submitted.

\section{Author Disclosure}

Both authors declared that there were no known conflict of interest and the institution did not have any financial or proprietary gain as to the results of the study.

\section{Funding Source}

This study was funded by the Department of Science and Technology - Science Education Institute (DOST-SEI) and implemented under the Department of Nutrition, College of Public Health, University of the Philippines Manila.

\section{REFERENCES}

1. Koen N, Blaauw R, Wentzel-Viljoen E. Food and nutrition labelling: the past, present and the way forward. South Afr J Clin Nutr. 2016; 29(1):13-21.

2. Philippine Nutrition Facts and Figures 2013. 8th National Nutrition Survey Overview. FNRI-DOST. 2015.

3. From Burden to Best buys": Reducing the economic impact of noncommunicable diseases in low and middle-income countries. World Economic Forum. Switzerland. 2011.

4. Azman N, Sahak SZ. Nutritional Label and Consumer Buying Decision: A Preliminary Review. Procedia-Social and Behavioral Sciences. 2014 May; 130:490-498.

5. Mandle J, Tugendhaft A, Michalow J, Hofman K. Nutrition labelling: a review of research on consumer and industry response in the global south. Glob Health Action. 2015 Jan; 8:25912.

6. Hawkes C. Nutrition labels and health claims: the global regulatory environment. WHO: France. 2004.

7. Summary Report: 9th Seminar on Nutrition Labeling, Claims and Communication Strategies. International Life Sciences Institute (ILSI). Manila, Philippines. 2015.

8. Baliclic MF. Filipino consumer's understanding and use of nutrition labels. UP Diliman. 2015.

9. Aygen FG. Determinants of nutrition label use among Turkish consumers. Int J Humanit Soc Sci. 2012 Apr; 2(7):53-70.

10. Campos S, Doxey J, Hammond D. Nutrition labels on pre-packaged foods: a systematic review. Public Health Nutr. 2011 Aug; 14(8): 1496-506.

11. Cowburn G, Stockley L. Consumer understanding and use of nutrition labelling: a systematic review. Public Health Nutr. 2005 Feb; 8(1):21-8.

12. Aryee GA. Awareness and use of nutrition labels on pre-packaged foods among consumers in Accra. 2013. Unpublished thesis.

13. Los Baños Gender and Development Database. Social Development Sector: Health subsector [Internet]. Los Baños GAD Database. 2018 [cited 2019 May]. Available from: www.losbanos.gov.ph.

14. Los Baños Facts and Figures [Internet]. 2015 [cited 2019 May]. Available from: www.losbanos.gov.ph.

15. Marrieta, AB, Welshimer KJ, Anderson SL. Knowledge, attitudes, and behaviors of college students regarding the 1990 Nutrition Labeling Education Act food labels. J Am Diet Assoc. 1999 Apr; 99(4):445-9.

16. Kliemann N, Wardle J, Johnson F, Croker H. Reliability and validity of a revised version of the General Nutrition Knowledge Questionnaire. Eur J Clin Nutr. 2016 Oct; 70(10):1174-80.

17. Mackison D, Wrieden WL, Anderson AS. Validity and reliability testing of a short questionnaire developed to asses consumers' use, understanding and perception of food labels. Eur J Clin Nutr. 2010 Feb; 64(2):210-7.

18. Roininen K, Lahteenmaki L, Tuorila H. Quantification of consumer attitudes to health and hedonic characteristics of foods. Appetite. 1999 Aug; 33(1):71-88. 
19. Francis J, Eccles MP, Johnston M, Walker AE, Grimshaw JM, Foy R, et al. Constructing questionnaires based on the theory of planned behavior: A manual for health services researchers. Newcastle upon Tyne, UK: Centre for Health Services Research, University of Newcastle upon Tyne; 2004.

20. Drichoutis AC, Lazaridis P, Nayga Jr. RM. Consumers' Use of Nutritional Labels: a Review of Research Studies and Issues. Academy of Marketing Science Review. No.9. 2006.

21. Nayga RM. Determinants of consumers' use of nutritional information on food packages. J Agric Appl Econ. 1996 Feb; 28(2):303-12.

22. Bureau of Agricultural Research. 2001. "GMA awards LGU's national nutrition achievers”. BAR Chronicle. 2001 Nov; 2(21-22).

23. Donga G, Patel N. A review of research studies on factors affecting consumers' use of nutritional labels. Nutri Food Sci Int J. 2018 Aug; 7(3):555713.

24. Grunert KG, Fernández-Celemín L, Wills JM, Bonsmann SSG, Nureeva L. Use and understanding of nutrition information on food labels in six European countries. Z Gesundh Wiss. 2010 Jun; 18(3):261-77.
25. Fila SA, Smith C. Applying the theory of planned behavior to healthy eating behaviors in urban native American youth. Int J Behav Nutr Phys Act. 2006 May; 3:11.

26. Wiles NL, Paterson M, Meaker JL. What factors determine the use of the nutrition information on the food label when female consumers from Pietermaritzburg select and purchase fat spreads? S Afr J Clin Nutr. 2009; 22(2):69-73.

27. Rasberry CN, Chaney BH, Housman JM, Misra R, Miller PJ. Determinants of Nutrition Label Use Among College Students. Am J Health Educ. 2007;3(2):76-82.

28. Song J, Huang J, Chen Y, Zhu Y, Li H, Wen Y, et al. The understanding, attitude and use of nutrition label among consumers. Nutr Hosp. 2015 Jun; 31(6):2703-10.

\section{The Acta Medica Philippina is now accepting limited advertising for its front and back cover (colored), as well as for available spaces in some of its pages, as appropriate. For inquiries and submission of proposals, please email us at actamedicaphilippina.upm@up.edu.ph}

